\title{
Isolation and genetic identification of spore-forming bacteria associated with concentrated-milk processing in Nebraska
}

\author{
Bismarck A. Martinez, ${ }^{*}$ Jayne Stratton, ${ }^{*} \dagger$ and Andreia Bianchini ${ }^{*}{ }^{1}$ \\ *Department of Food Science and Technology, and \\ †The Food Processing Center, University of Nebraska-Lincoln, Lincoln 68588
}

\begin{abstract}
Spore-forming bacteria are heat-resistant microorganisms capable of surviving and germinating in milk after pasteurization. They have been reported to affect the quality of dairy products by the production of enzymes (lipolytic and proteolytic) under low-temperature conditions in fluid milk, and have become a limiting factor for milk powder in reaching some selective markets. The objective of this research was to isolate and identify the population of spore-forming bacteria (psychrotrophic and thermophilic strains) associated with concentrated milk processing in Nebraska. During 2 seasons, in-process milk samples from a commercial plant (raw, pasteurized, and concentrated) were collected and heat-treated $\left(80^{\circ} \mathrm{C} / 12 \mathrm{~min}\right)$ to recover only spore-formers. Samples were spread-plated using standard methods agar and incubated at $32^{\circ} \mathrm{C}$ to enumerate mesophilic spore counts. Heat-treated samples were also stored at $7^{\circ} \mathrm{C}$ and $55^{\circ} \mathrm{C}$ to recover spore-formers that had the ability to grow under those temperature conditions. Isolates obtained from incubation or storage conditions were identified using molecular techniques (16S or $r p o B$ sequencing). Based on the identification of the isolates and their relatedness, strains found in raw, pasteurized, and concentrated milk were determined to be similar. Paenibacillus spp. were associated with both raw and concentrated milk. Due to their known ability to cause spoilage under refrigeration, this shows the potential risk associated with the transferring of these problematic organisms into other dairy products. Other Bacillus species found in concentrated milk included Bacillus clausii, Bacillus subtilis, Lysinibacillus sp., Bacillus safensis, Bacillus licheniformis, Bacillus sonorensis, and Brevibacillus sp., with the last 3 organisms being capable of growing at thermophilic temperatures. These strains can also be translocated to other dairy products, such as milk powder, representing a
\end{abstract}

Received July 6, 2016.

Accepted October 19, 2016.

${ }^{1}$ Corresponding author: abianchini2@unl.edu quality problem. The results of this research highlight the importance of understanding spore-formers associated with the processing of condensed milk, which then may allow for specific interventions to be applied to control these microorganisms in this processing chain. To our knowledge, this is the first study evaluating spore-formers associated with concentrated milk in the United States.

Key words: spore-forming bacteria, thermophilic, mesophilic, processing

\section{INTRODUCTION}

Spore-forming bacteria are often present in dairy products, ranging from raw milk to packaged products, due to their ability to survive different heat treatments including the pasteurization process (Huck et al., 2008; Ranieri et al., 2009). These bacterial communities are widely distributed in dairy farm environments and are easily introduced into raw milk and at subsequent points during handling and processing (te Giffel et al., 2002; Magnusson et al., 2007; Watterson et al., 2014). More importantly, the presence of certain spore-forming strains may produce quality defects in different dairy products. For the fluid milk industry, psychrotrophic spore-formers are an issue due to the reduction of shelf-life during refrigerated storage caused by the ability of these strains to produce different enzymes (lipolytic and proteolytic) at low temperatures (Meer et al., 1991). Among those spore-former species are Paenibacillus spp., Viridibacillus spp., and Bacillus weihenstephanensis (Fromm and Boor, 2004; Ivy et al., 2012; Estrada, 2014).

For the milk powder industry, high levels of sporeformers $(>500$ spores $/ \mathrm{mL})$ in the final product limits their potential markets, leading to loss of opportunities when quality standards of more profitable markets (e.g., global and infant formula markets) cannot be met (Bienvenue, 2014). Some spore-former strains can germinate and grow under warm $\left(45-60^{\circ} \mathrm{C}\right)$ conditions; therefore, these thermophilic strains are of special interest to this industry due their ability to grow and 
establish themselves on equipment surfaces during processing (Burgess et al., 2010; Watterson et al., 2014).

Commercial sweetened condensed milk typically contains high sugar levels, which are usually added during processing, followed by a final canning step. Due to the addition of these multiple hurdles, such as high osmotic pressure and a killing step, the final product is rendered safe and shelf-stable. It is believed that the main spore-former bacteria surviving this heat treatment are thermophilic strains (i.e., Bacillus licheniformis, Bacillus coagulans, Bacillus macerans, Bacillus subtilis, and Geobacillus stearothermophilus). Therefore, their growth is limited when product is stored at room temperature conditions $\left(<43^{\circ} \mathrm{C}\right)$, especially when osmotic pressure is an additional hurdle (Karaman and Alvarez, 2014).

When concentrated or evaporated milk is used as an ingredient, it may not require a heating step (i.e., canning) or the addition of sugars. However, this product is still susceptible to bacterial spoilage and refrigeration is required to maintain its integrity until further use (Karaman and Alvarez, 2014). This intermediate product is used to produce a multitude of other dairy products, including spray-dried milk powder, yogurt, pudding, and cheeses. Therefore, concentrated milk may serve as a vehicle for spore-formers, leading to potential contamination of consumer products. The quality and the safety of those foods could be at risk if strains with the ability to affect their quality or safety (i.e., Bacillus cereus or toxigenic strains) are present. Due to these multiple issues caused by spore-formers in different dairy sectors, the dairy industry is interested in understanding this bacterial population.

To date, spore-forming bacteria associated with concentrated milk produced in the United States has not been well described. It is not clear if the main entry point of spore-formers is the raw milk or perhaps processing equipment due to the conditions encountered during the manufacturing of condensed milk. Therefore, the objective of our research was to isolate and genetically identify spore-forming bacteria (psychrotrophic and thermophilic strains) associated with a concentrated milk processing facility in Nebraska.

\section{MATERIALS AND METHODS}

\section{Collection and Analysis of Samples}

Samples of raw milk were collected during spring (April) and fall (October) 2014 from a concentrated skim milk processing facility in Nebraska. In each season, samples were collected from tankers $(\mathrm{PR}, \mathrm{Cl}$, and DF; samples were given random letters to maintain confidentiality) representing different farms that deliver at the processing facility. From each tanker, samples were collected in duplicate and raw milk was transferred from trucks to silos using a QMI (QualiTru Sampling System, Oakdale, MN) aseptic sampling system with a 250-mL sterile bag. One sample was also collected from each raw milk silo (bulk milk cooling tank numbers 4 and 5; BM4 and BM5), and 1 additional sample was collected immediately before the pasteurizer (Figure 1). Similarly, pasteurized milk samples (collected after pasteurization and before the evaporation process, at the evaporator) and concentrated skim milk samples (collected at holding tanks) were obtained in duplicate during each season using the QMI aseptic system (250$\mathrm{mL}$ bags). Samples from evaporator and final holding tanks were collected in the middle of a processing run, which usually is no longer than $5 \mathrm{~h}$. A diagram of sampling points at the processing plant and the number of samples collected in each season per sampling point are represented in Figure 1. All collected samples were stored under refrigeration at the plant until they were transported to the laboratory. During transport they were maintained on ice and upon arrival they were processed. The whole process of sample collection and transport never exceeded $24 \mathrm{~h}$.

The selected processing plant produces mostly class II and III concentrated milk, which is an ingredient to produce yogurt, pudding, cottage, and other cheeses. The commercial plant uses a pasteurization protocol of $75^{\circ} \mathrm{C}\left(167^{\circ} \mathrm{F}\right)$ per $20 \mathrm{~s}$. The evaporation process runs at $61.1^{\circ} \mathrm{C}\left(\sim 142^{\circ} \mathrm{F}\right)$ for $20 \mathrm{~min}$ and, finally, concentrated milk is stored at $1.6^{\circ} \mathrm{C}\left(\sim 35^{\circ} \mathrm{F}\right)$ for future use. Process fluctuations were within $1^{\circ} \mathrm{C}$.

For all collected samples, microbial quality was determined, including total plate count (TPC), coliforms (Col), Escherichia coli (EC), yeast count (YC), molds counts (MC), and mesophilic spore counts (MSC). The detection limit was equal to $1 \mathrm{cfu} / \mathrm{mL}$ for all microbial methods previously mentioned. These analyses were performed with the intent to describe the microbial quality of the milk entering into the processing facility and the in-process product. Figure 2 shows the steps performed for microbial analysis in raw, pasteurized, and concentrated milk samples.

For detection of spore-formers, milk samples (250 $\mathrm{mL}$ collected at processing plant) were homogenized in the laboratory by thoroughly mixing the contents of the bag, and aliquots $(150 \mathrm{~mL})$ were transferred into sterile $250-\mathrm{mL}$ screw-capped bottles. Vegetative cells were killed by heating samples at $80^{\circ} \mathrm{C}$ for $12 \mathrm{~min}$, using a temperature-controlled water bath (model 148007, Bockel Industries, Philadelphia, PA). This method has been widely used for the isolation of spore-formers by other research groups (Ivy et al., 2012; Estrada, 2014). 


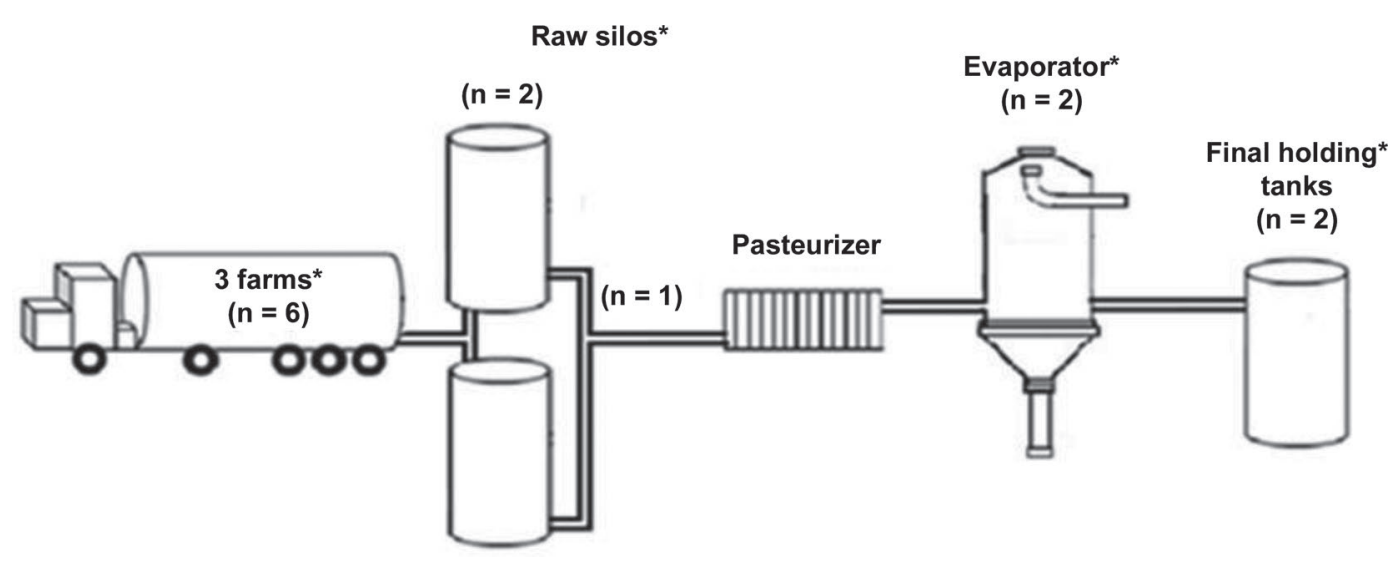

Figure 1. Simplified diagram of the concentrated milk plant. Concentrated processing plant receives raw milk from farms located in different areas of Nebraska. Marked equipment $(*)$ represent the points where samples were collected for analysis, and $\mathrm{n}$ represents the number of samples collected per season.

Samples were heat-treated in groups of 5 based on sample similarities (i.e., raw milk samples were processed together) and temperature was closely monitored. After the heat treatment had been performed, bottles containing samples were cooled immediately using an ice bath.

Microbiological analyses performed on these heattreated samples are listed on section B of Figure 2. All heat-treated samples were enumerated for aerobic mesophilic spore-former counts [standard methods agar (SMA), $32^{\circ} \mathrm{C}$ for $48 \mathrm{~h}$ ] and psychrotrophic spore- former counts (SMA, $7^{\circ} \mathrm{C}$ for $7 \mathrm{~d}$ ). Those plates used for counting were also used to isolate spore-formers. At least 4 different isolates were selected from each sample based on their morphology and added to the culture collection for further analysis (as listed in Figure 2C).

To improve the recovery of the mesophilic sporeformers and potentially allow for the isolation of thermophilic spore-formers, an enrichment was performed in subsamples of raw and skim concentrated milk. Aliquots $(30 \mathrm{~mL})$ from heat-treated samples were incubated at $32^{\circ} \mathrm{C}$ and $55^{\circ} \mathrm{C}$ for $48 \mathrm{~h}$ to increase the number

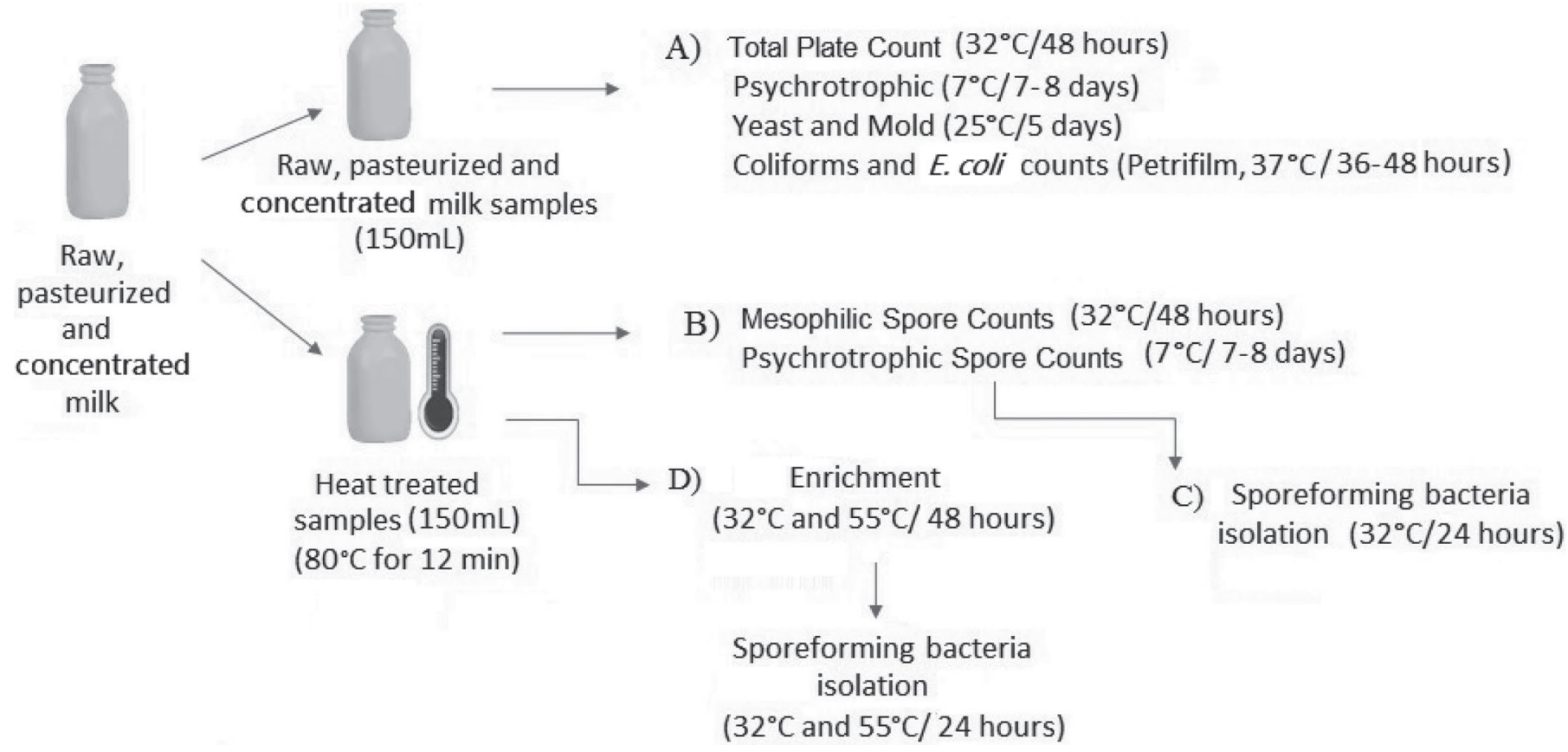

Figure 2. Procedures for microbial analysis performed in raw, pasteurized, and concentrated milk samples each season. 
of mesophilic and thermophilic spore-formers, respectively. Finally, samples were spread plated on SMA and incubated at the same temperatures for $24 \mathrm{~h}$ to allow for additional isolation of mesophilic and thermophilic spore-formers, respectively (Figure 2D).

Heat-treated raw milk samples were stored at $7^{\circ} \mathrm{C}$ in a low-temperature incubator (VWR 3734, VWR International, Radnor, PA) for $21 \mathrm{~d}$ to provide a conducive environment for psychrotrophic spore-formers to germinate and grow, if present. Samples were then enumerated by serially dilution on SMA on d $0,7,14$, and 21 post-treatment and incubation at $32^{\circ} \mathrm{C}$ for $48 \mathrm{~h}$ (Laird et al., 2004). This procedure allows quantification of psychrotrophic spore-formers throughout the refrigerated storage period. According to the Pasteurized Milk Ordinance (PMO), pasteurized milk cannot exceed more than 20,000 (4.3 log) cfu/mL (FDA, 2015) during storage; therefore, samples containing greater bacterial counts at any storage time point were considered as potentially spoiled product, and those spore-formers present were considered as potential problematic strains. From plates used for enumeration, 4 different strains were isolated from each sample or time point based on their different morphologies. These strains were also added to the culture collection for further analysis.

From all samples, strains were isolated using the following protocol. Samples were streaked for isolation and purification on SMA and incubated at $32^{\circ} \mathrm{C}$ for 48 $\mathrm{h}$. Individual bacterial colonies were then transferred to tryptic soy broth (TSB) and incubated at $32^{\circ} \mathrm{C}$ for 48 $\mathrm{h}$ to allow for growth before long-term storage. Finally, pure strains were stored in TSB containing $15 \%$ glycerol at $-80^{\circ} \mathrm{C}$.

More than 100 isolates from each season were targeted for sequencing using the rpoB gene/16S gene (72 isolates were sequenced from raw milk samples and 32 isolates from concentrated and pasteurized milk). Two seasons were analyzed in our study (spring 2014 and fall 2014).

\section{DNA-Based Identification Method}

Pure strains from the culture collection were reactivated by streaking on SMA and incubating at $32^{\circ} \mathrm{C}$ for $48 \mathrm{~h}$. After incubation $\left(32^{\circ} \mathrm{C}\right.$ for $\left.48 \mathrm{~h}\right)$, strains were transferred to TSB. The methodology for DNA extraction and analysis are described in detail in the following sections.

Extraction and Preparation of DNA. Briefly, $1 \mathrm{~mL}$ of overnight cultures was transferred to sterile bead-beating tubes (containing $300 \mathrm{mg}$ of zirconium beads) and tubes were placed on ice. Bacterial cells were recovered by centrifugation at $8,000 \times g$ for $5 \mathrm{~min}$ at room temperature (Microcentrifuge 16, BeckmanCoulter Inc., Brea, CA). The supernatant was discarded and $180 \mu \mathrm{L}$ of lysis buffer containing $20 \mathrm{mg} / \mathrm{mL}$ of lysozyme was added to the tube (Thermo Fisher Scientific, Waltham, MA). Cell pellets were resuspended by vortexing, followed by incubation at $37^{\circ} \mathrm{C}$ for $30 \mathrm{~min}$ (Estrada, 2014). Subsequently, a QIAmp DNA minikit (Qiagen Inc., Valencia, CA) was used to further extract DNA according to the manufacturer recommendations.

PCR Reaction. Once the DNA had been extracted, a PCR method was used to multiply the $r p o B$ gene. A DNA fragment of about 632 nucleiotides of the rpoB gene-1, as described by Huck et al. (2007a,b), was amplified using the primers described by Drancourt et al. (2004) and PCR conditions by Durak et al. (2006). Forward primer (5'-AAR YTI GGM CCT GAA GAA AT-3') and reverse primer (5'-TGT ART TTR TCA TCA ACC ATG TG-3') were diluted to a final concentration of 20 to $40 \mathrm{pmol} / \mu \mathrm{L}$. Takara (Shiga, Japan) PCR reagents were used for the PCR reaction, including $5 \mathrm{U} / \mu \mathrm{L}$ of polymerase added in a total solution of $100 \mu \mathrm{L} /$ reaction. All of the reagents were mixed in a PCR tube and all reactions were performed using a thermocycler (T100, Bio-Rad, Hercules, CA). The PCR products were detected by agarose gel electrophoresis (1\% agarose, $60 \mathrm{~V}$ for $2 \mathrm{~h}$ ). Those PCR reactions that yielded an appropriate DNA product (with the right base pair size) were considered successful and their products used for further analysis.

Purification of PCR Products. The PCR purification was done using a QUIAquick Purification Kit (Qiagen Inc.) according to manufacturer recommendations. This procedure included the PCR products purified using a column to remove the remaining PCR pair bases. This purification was necessary to ensure good quality results during sequencing.

DNA Quantification. Quantification of the amplified DNA was required to verify and adjust the material to the right concentration to perform the sequencing procedure. A NanoDrop 1000 spectrophotometer (NanoDrop Technologies, Wilmington, DE) was used to accurately quantify the amount of amplified DNA present after the purification step. This concentration was adjusted to $40 \mathrm{ng} / \mu \mathrm{L}$ according to the sequencing technology requirements based on the size of the DNA fragment.

DNA Sequencing. Purified DNA was sent for bidirectional sequencing with Big Dye Terminator chemistry at Eurofins MWG Operon (Louisville, KY). Based on the results, DNA sequences were aligned and trimmed to 632 nt rpoB fragments in BioEdit (Ibis Biosciences, Carlsbad, CA), version 7.1.11, to obtain high-quality data as described by Durak et al. (2006). 
Ambiguities were resolved by examination of the obtained chromatogram or the strain was identified using an alternative molecular method (i.e., $16 \mathrm{~S}$ portion). Only high-quality, double-stranded sequences were used for further analysis based on the rpoB gene. Different allelic types (AT) were assigned according to gene sequences from each strain, where a single difference in pair base was considered as a different AT (Huck et al., 2007a,b). This AT assignment allowed strains of closely related organisms to be distinguished and serve as a tool to determine potential spore-former contamination sources.

\section{Alternative Approach}

The proposed rpoB gene amplification method is based on a single-copy gene present in prokaryotes. Due to this characteristic, the method requires high DNA quantity to be able to amplify the desired fragment during the PCR reaction. This may not be possible for all isolates, whereas others may allow for amplification but their sequences do not match any previously reported ones on the databases used in this project. In either case, identification of the isolate is not possible using the $r p o B$ gene. Therefore, an alternative amplification method of a more conserved region (based on the 16S rDNA section) was used for those isolates. Different from the rpoB fragment, the $16 \mathrm{~S}$ rDNA section has multiple copies in a single bacterium and, even though it is more conserved, it still provides enough variability to allow for genus and species identification. Even though this alternative approach does not provide subtyping information, as the $r p o B$ gene does, it is sufficient to identify those isolates that otherwise would be unknown. According to previous results (Estrada, 2014), those cases could account for $10 \%$ of all sequenced strains. This alternative approach used a PCR reaction with similar conditions as described by Fromm and Boor (2004), including the forward primer (5'-GCA AAC AGG ATT AGA TAC CC-3') and reverse primer (5'-AGG AGG TGA TCC AAC CGC A-3'; Rothman et al., 2002; Greisen et al., 1994).

\section{Strain Identification and Construction of Phylogenetic Trees}

The fragments obtained by amplification of the rpo $B$ gene and $16 \mathrm{~S}$ portion of the DNA were used for strain identification. This identification was performed by comparison of the sequences to information deposited in 2 available databases - Basic Local Alignment Search Tool (BLAST; blast.ncbi.nlm.nih.gov/Blast.cgi) and Food Microbe Tracker (www.foodmicrobetracker. $\mathrm{com} /$ ) - the latter more specific for Bacillus (species and related groups) associated with dairy products (Vangay et al., 2013).

The sequences from all collected isolates throughout the storage period from heat-treated milk samples (raw, pasteurized, and concentrated skim milk) were used to create phylogenetic trees for the concentrated milk chain. To construct the trees, DNA sequences (representing each AT identified using rpoB) were aligned using Muscle in MEGA6. Phylogenetic trees were constructed using the neighbor-joining method with 2,000 bootstrap replicates in MEGA6 (Tamura et al., 2013). Streptococcus pyogenes (NC_004070) was used as an out group according to Huck et al., (2007b). Similarly, phylogenetic trees were also constructed using the sequences obtained from amplification of the 16S DNA section.

The phylogenetic trees (16S and rpoB) were used to group isolates in clades, based on their genetic relatedness. Cutoff values helped to define those clades, and those values were established using bootstrap values generated by the neighbor-joining method during phylogenic tree construction. To assign each different clade, a bootstrap value of at least 70 was used.

Isolates representing each different clade of the tree were characterized based on information available in the literature. This characterization allowed for the classification of some isolates as psychrotrophic sporeformers. Those isolates characterized as psychrotrophic, along with other members of the same clade, were classified as potentially problematic spore-formers for the fluid milk chain.

All collected isolates from concentrated milk were classified as transferable spore-formers, as they were able to survive processing (pasteurization and condensation). These strains would most likely be relocated into other dairy products when concentrated milk is used as an ingredient (cheese, yogurt, or powdered milk).

\section{RESULTS AND DISCUSSION}

\section{Microbial Quality of Milk in the Concentrated Milk Plant}

Raw milk samples from 3 farms in Nebraska were collected for microbial quality analysis upon arrival at the concentrated milk processing plant. From each farm, at least 2 samples were collected per season (spring and fall) for year 2014. Samples were treated independently during analysis. Microbial counts for raw milk are shown by season in Table 1, whereas processed milk (pasteurized and concentrated milk data) is shown in Table 2. 
Table 1. Microbial analysis of raw milk from different farms and silos collected at a concentrated skim milk plant; values represent the average of the bacterial population present on samples collected during 2 seasons ${ }^{1}$

\begin{tabular}{|c|c|c|c|c|c|c|c|c|}
\hline \multirow[b]{2}{*}{ Product (season) } & \multirow[b]{2}{*}{ Sampling point } & \multicolumn{5}{|c|}{$\log \mathrm{cfu} / \mathrm{mL}$} & \multirow[b]{2}{*}{ MSC } & \multirow[b]{2}{*}{$\mathrm{PBC}$} \\
\hline & & $\mathrm{TPC}$ & $\mathrm{COL}$ & $\mathrm{EC}$ & $\mathrm{YC}$ & $\mathrm{MC}$ & & \\
\hline & Silo BM5 & 3.74 & 1.92 & 1.66 & 2.59 & ND & 1.17 & 1.94 \\
\hline & Farm Cl & 3.57 & 2.86 & 1.68 & 1.84 & 0.15 & 1.13 & 2.40 \\
\hline & Farm Pr & 3.07 & 0.68 & ND & 1.06 & 0.35 & 1.10 & 1.92 \\
\hline (fall) & Silo BM4 & 4.16 & 2.46 & 1.47 & 2.53 & 0.15 & 0.57 & 1.92 \\
\hline & Silo BM5 & 3.92 & 2.8 & 1.47 & 2.68 & ND & 0.47 & 2.65 \\
\hline & Farm Cl & 3.94 & 3.06 & 2.08 & 2.46 & 0.80 & 1.30 & 2.91 \\
\hline & Farm $P r$ & 3.18 & 1.83 & 1.38 & 2.40 & 0.65 & 1.41 & 2.82 \\
\hline & Average & 3.48 & 2.43 & 1.37 & 2.51 & 0.45 & 0.98 & 2.56 \\
\hline
\end{tabular}

${ }^{1} \mathrm{TPC}=$ total plate counts; $\mathrm{COL}=$ coliforms counts; $\mathrm{EC}=$ Escherichia coli counts; $\mathrm{YC}=$ yeast counts; $\mathrm{MC}=$ mold counts; MSC $=$ mesophilic spore counts; $\mathrm{PBC}=$ psychrotrophic bacteria counts; $\mathrm{ND}=$ not detected (below the detection limit $<1 \mathrm{cfu} / \mathrm{mL}$ ).

Regarding the raw milk quality, microbial results showed that milk samples (from both seasons) were within the regulatory limits for grade A milk (raw milk from 1 farm $<5 \log \mathrm{cfu} / \mathrm{mL}$ ) established by the PMO for TPC (FDA, 2015). Moreover, commingled samples at plant (from raw silos) were also within the standards $(<5.8 \log \mathrm{cfu} / \mathrm{mL}$ if commingled), suggesting good quality of the milk before processing (Table 1). This result indicates that microbial milk quality was maintained from farm to processing plant with less than 4 $\log \mathrm{cfu} / \mathrm{mL}$, showing that good hygienic practices were used during earlier stages of processing. For raw milk, the PMO regulation does not specify limits for Col, EC, $\mathrm{YC}, \mathrm{MC}$, and MSC; therefore, these counts should be considered only as part of the characterization of the milk quality. Regarding MSC, raw milk counts varied from 0.30 to $1.80 \log \mathrm{cfu} / \mathrm{mL}$, which was found to be in agreement with previous studies performed in the Midwest region (South Dakota; Buehner et al., 2014) and the eastern United States (New York; Miller et al., 2015).

Moreover, pasteurized milk samples from the concentrated plant indicated that bacterial populations (TPC) after pasteurization were around $2 \mathrm{log} \mathrm{cfu} / \mathrm{mL}$ (regardless of the season), which is lower than the standard required by the PMO $(<4.3 \log \mathrm{cfu} / \mathrm{mL})$. Processed samples (pasteurized) showed MSC at slightly higher levels than the ones observed for raw milk at the plant (raw silos and raw milk), which can be explained by potential cross-contamination by spore-formers during processing. Therefore, these results highlight the importance of raw milk quality with lower spore-forming bacteria, but also the importance of proper sanitation protocols within the plant to avoid cross-contamination and keep low spore counts during processing and in the final product. Psychrotrophic bacteria counts and psychrotrophic spore counts were mostly detectable in concentrated milk samples stored in refrigerated hold-

Table 2. Microbial analysis of pasteurized and concentrated milk collected at a concentrated skim milk plant; samples described in this table were collected in 2 different seasons ${ }^{1}$

\begin{tabular}{llccc}
\hline & & \multicolumn{3}{c}{ Log cfu/mL } \\
\cline { 3 - 5 } Product (season) & Sampling point & TPC & MSC & PBC \\
\hline Pasteurized milk (spring) & Pasteurizer/evaporator & 2.26 & 1.9 & ND \\
Concentrated milk (spring) & Pasteurizer/evaporator & 2.32 & 2 & ND \\
& Holding tanks & 2.4 & 2.2 & 1.00 \\
Pasteurized milk (fall) & Holding tanks & 1.91 & 1.84 & ND \\
Concentrated milk (fall) & Holding tanks & 1.76 & 1.69 & 1.20 \\
& Pasteurizer/evaporator & 1.20 & 1.26 & ND \\
& Pasteurizer/evaporator & 2.04 & 2.27 & 0.78 \\
& Holding tanks & 2.91 & 2.27 & 0.90 \\
& Holding tanks & 2.04 & 2.19 & 1.20 \\
\hline
\end{tabular}

${ }^{1} \mathrm{TPC}=$ total plate counts; $\mathrm{MSC}=$ mesophilic spore counts; $\mathrm{PBC}=$ psychrotrophic bacteria counts; $\mathrm{ND}=$ not detected (below the detection limit $<1 \mathrm{cfu} / \mathrm{mL}$ ). 
ing tanks, which may indicate a potential long-term association of psychrotrophic organisms with the tanks, leading to a cross-contamination of concentrated milk when stored in those tanks. Additionally, Col, EC, YC, and $\mathrm{MC}$ were performed but, as expected, those counts were under the detection limit $(<1 \mathrm{cfu} / \mathrm{mL}$; data not shown). The PMO does not have a standard for TPC for concentrated milk products, but Col should be less than $10 \mathrm{cfu} / \mathrm{mL}$ (FDA, 2015). According to the results presented here, samples from pasteurized and condensed/concentrated milk were within the coliform standard provided by the PMO.

\section{Presence of Spore-Formers in Fluid Milk Throughout Refrigerated Storage}

To determine the prevalence of psychrotrophic sporeformers, heat-treated raw milk samples (TB1-TB9 from both seasons) were stored at refrigeration temperature $\left(7^{\circ} \mathrm{C}\right)$ for $21 \mathrm{~d}$ and bacterial growth was determined by plate counts. Samples in which bacterial growth reached $4.3 \log \mathrm{cfu} / \mathrm{mL}$ (limit given by the PMO) or greater were considered to contain potentially problematic psychrotrophic spore-formers.

Two samples analyzed on spring 2014 (TB8 and TB7) showed growth of psychrotrophic spore-formers $(\geq 4.3 \log \mathrm{cfu} / \log )$. These samples represented raw milk coming from 2 different farms. Sequencing analysis revealed that at least 3 different AT of Paenibacillus spp. were found in these samples.

One AT found in a sample (TB7) has been identified as Paenibacillus odorifer (AT130) by the rpoB gene. Recent characterization of the same rpo $B$ allelic type was reported by other researchers (Trmčić et al., 2015), who described this strain as capable of growing under refrigeration temperature $\left(6^{\circ} \mathrm{C}\right)$ and producing $\beta$-galactosidase, which could enhance the utilization of simple sugars by bacterial metabolism. A similar result was found for sample TB8, in which Paenibacillus odorifer was isolated 2 consecutive times after refrigerated storage (14, $21 \mathrm{~d}$ ) using $16 \mathrm{~S}$ and rpoB analysis (AT49). Therefore, the bacterial growth observed during refrigeration in both samples is not surprising once some of the organisms present were identified at the strain level (i.e., AT). More important to note is that these problematic AT are not necessarily region specific, as the same strains appear to be present in different regions of the United States.

Similarly, for samples collected during fall 2014, 3 samples (TB2, TB6, and TB7) showed high populations of spore-formers after refrigerated storage for $21 \mathrm{~d}$. In the sample identified as TB2, 3 allelic types were found: Paenibacillus cookii, Paenibacillus graminis
(AT116), and Paenibacillus spp. (16S DNA). In sample TB6, B. cereus (AT162) ATCC 10987, which is potentially pathogenic in humans (Rasko et al., 2004), and P. odorifer (AT110), named as FSL F4-077 by another research group (Durak et al., 2006), were found. In sample TB7, 4 Paenibacillus AT were identified: $P$. odorifer (AT125), P. odorifer (AT049), and 2 Paenibacillus spp. (16S DNA).

In fact, several species described in the Paenibacillus genus (P. odorifer, P. graminis, Paenibacillus amylolyticus, Paenibacillus cf. xylanilyticus) have shown the ability to produce $\beta$-galactosidase and were previously described by Ivy et al. (2012). However, further characterization may be needed for some of the AT recovered in our study from heat-treated raw milk samples to verify their ability to grow at low temperatures, to determine their growth rates, and their ability to use lactose as a source of energy. Even though full characterization of these AT have not been performed yet, some of them belong to the same phylogenetic clades as others that have been characterized by their ability to grow at low temperature and produce $\beta$-galactosidase (Ivy et al., 2012). Therefore, these strains should be considered as potentially problematic for the fluid milk industry.

\section{Genetic Diversity of Isolates Obtained from Raw Milk}

Sequencing analysis led to the construction of a phylogenetic tree based on the collected isolates from raw milk at the processing plant. A wide diversity of spore-formers can be observed in Figure 3, which includes different genus, species, and related groups. This phylogenetic tree was constructed using 106 rpo $B$ sequences of isolates obtained from samples collected during both seasons, spring 2014 (50 sequences) and fall 2014 (56 sequences), and throughout refrigerated storage of heat-treated raw milk samples. In the same figure, isolates obtained from both seasons for fluid and condensed milk are described.

The phylogenetic tree in Figure 3 indicates that isolates could be subdivided into 2 major clusters, the Bacillus-related species cluster (which includes groups I, II, III, and IV) and the Paenibacillus genus cluster (group V). These 2 spore-former clusters have been described as the main clusters in milk chains by different research groups (Ivy et al., 2012; Estrada, 2014).

Group I consists of a Bacillus group, which is phylogenetically well supported (BS 85) and includes the following sensu lato (s.l.) groups: Bacillus safensis s.l. (i.e., B. subtilis and Bacillus pumilus), Bacillus aerophilus s.l. (i.e., B. aerophilus, Bacillus stratosphericus, and Bacillus altitudinis), B. licheniformis, and B. subtilis 


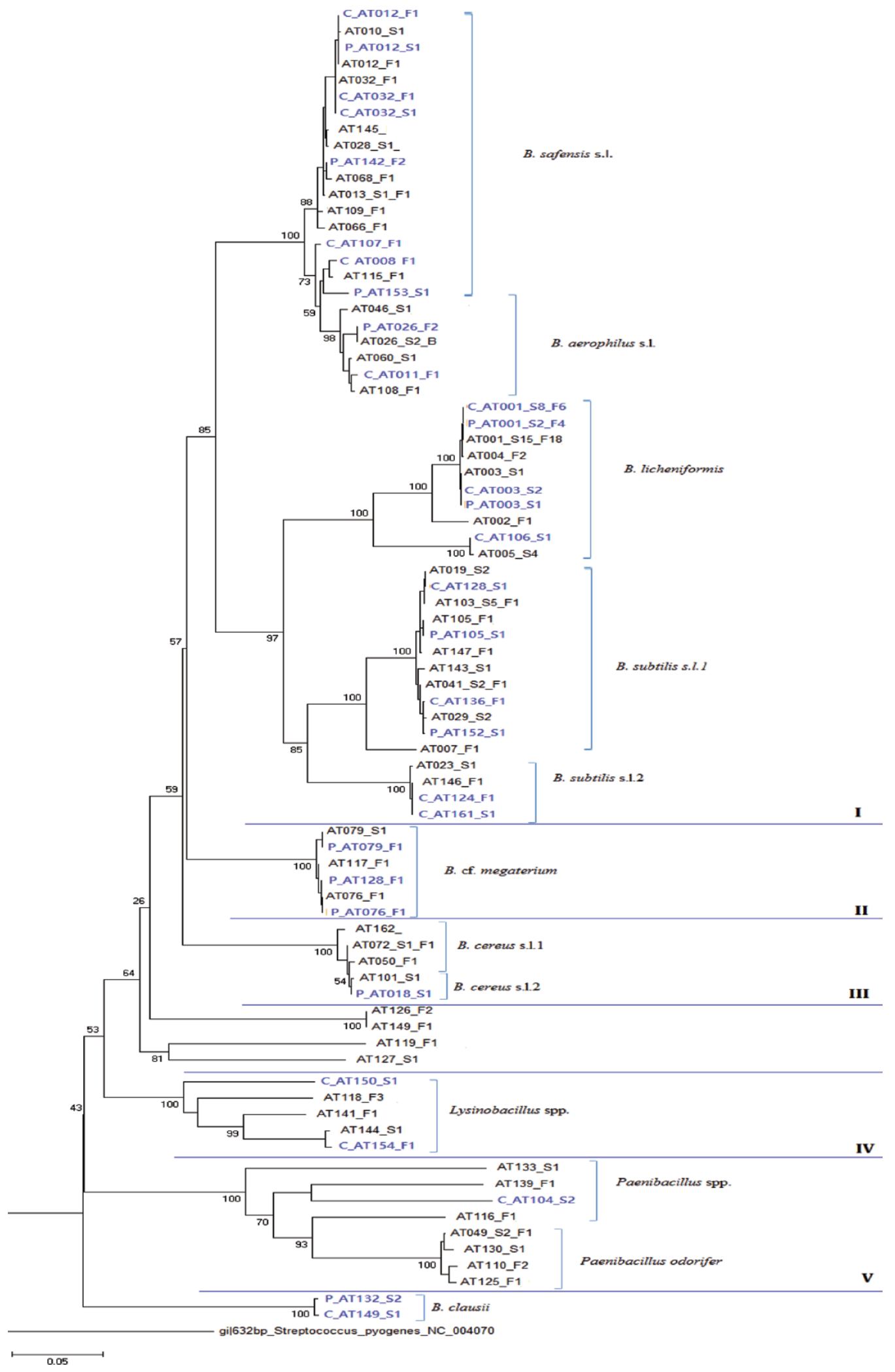

Figure 3. RpoB phylogenetic tree based on isolate sequences obtained from raw (black font or no prefix), pasteurized (blue font or prefix $\mathrm{P}$ ), and concentrated (blue font or prefix C) milk samples at the processing plant. Allelic types are labeled (AT) followed by 3-digit numbers for identification of each isolate. A suffix after the AT numbers was added to indicate the season $(\mathrm{S}=$ spring; $\mathrm{F}=$ fall $)$ and the number of isolates collected. B. = Bacillus. Color version available online. 
s.l. 1, 2 (i.e., Bacillus mojavensis, B. subtilis, among others). Group II includes Bacillus cf. megaterium. Group III is represented in the phylogenetic tree by $B$. cereus s.l. 1 and 2 (i.e., B. cereus, Bacillus thuringiensis, B. weihenstephanensis, Bacillus anthracis, Bacillus pseudomycoides, and Bacillus mycoides). Group IV includes Lysinobacillus spp., whereas group V includes Paenibacillus-related species.

Among the isolates reported here, there were AT that had not been previously reported in Nebraska (Estrada, 2014). These AT received identification numbers over 100 and can be observed in Figure 3. These new AT represented 51\% (26/51) from all sequences obtained from raw milk isolates. From these 26 new AT, 18 were isolated from fall 2014 samples, whereas only 8 new strains were found in spring 2014. This may indicate a wider diversity of Bacillus (AT) in the environment during fall than in spring. The implication of such greater diversity of spore-formers found in ingredients, such as raw fluid milk, at certain times of the year is related to a potential increase in their ability to negatively affect multiple sectors of the dairy industry when the quality of end products is considered.
The phylogenetic tree (Figure 3) also indicates the number of times each isolate (AT) was found in raw milk samples collected at the concentrated milk plant and the season(s) when it was found. For example, the letter $\mathrm{S}$ is used for spring and $\mathrm{F}$ for fall, followed by the number of times that a particular AT was found in raw milk in that season.

Some of the isolates, however, could not be amplified by the $r p o B$ primers (or sequencing did not match any previously reported isolate on databases used in this research). In those cases, the $16 \mathrm{~S}$ portion was then used to identify the genus and potential species to which those isolates belonged. When this alternative method was used, the identification was completed mostly at genus level, with some isolates being identified at species level. Because of the close proximity of multiple species in these genera, based on this portion of DNA, identification at strain level was not possible. Even with these limitations, information gathered using the $16 \mathrm{~S}$ portion of the DNA is still complimentary to what is achieved using the $r p o \mathrm{~B}$ gene sequencing. Therefore, to understand the distribution of the identified bacterial isolates, information from both identification methods

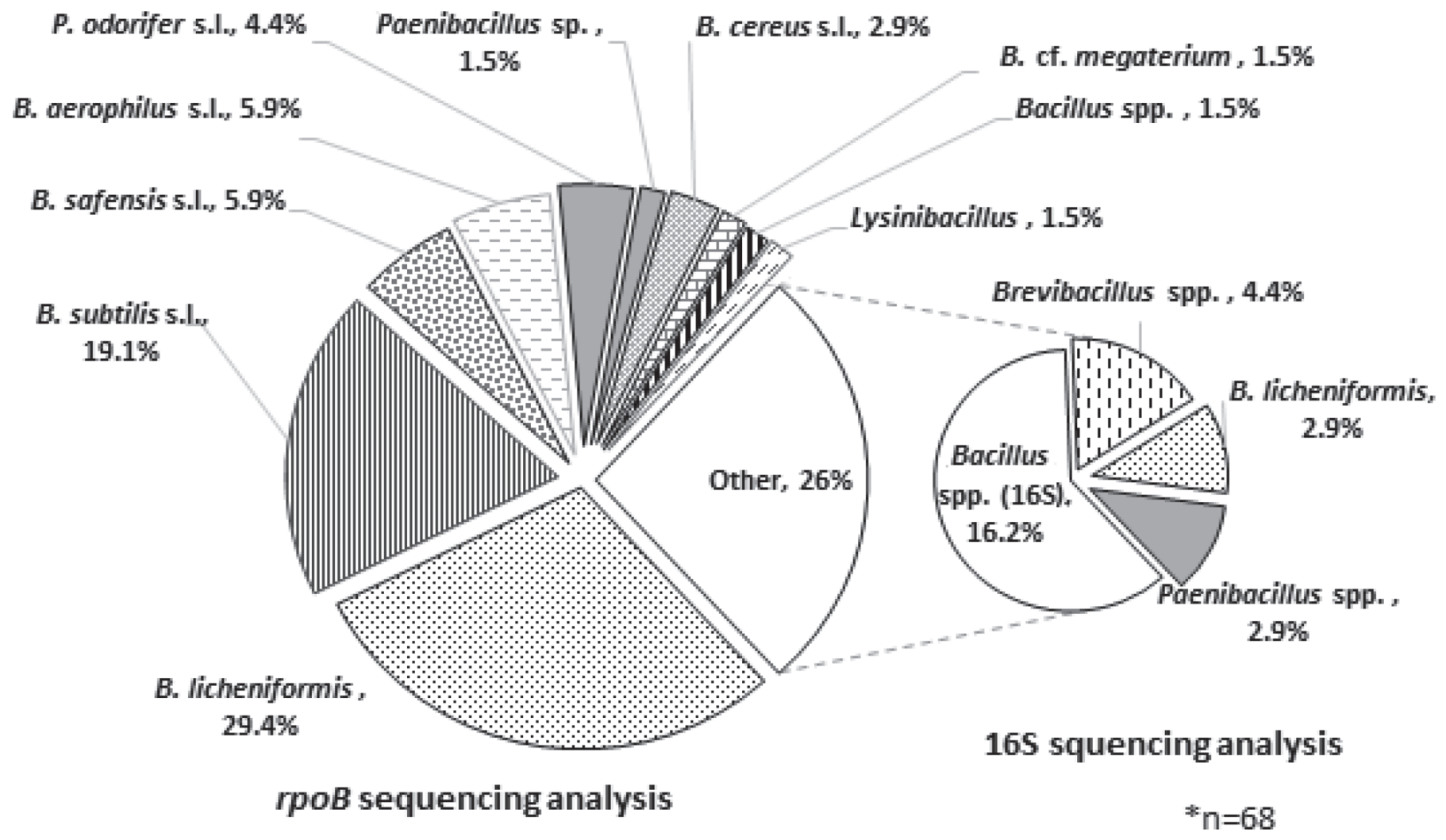

Figure 4. Identification of isolates from raw milk during spring 2014 using the $r p o B$ gene and the $16 \mathrm{~S}$ DNA portion (n $=$ number of total strains identified). B. = Bacillus, $P .=$ Paenibacillus, s.l. $=$ sensu lato. 


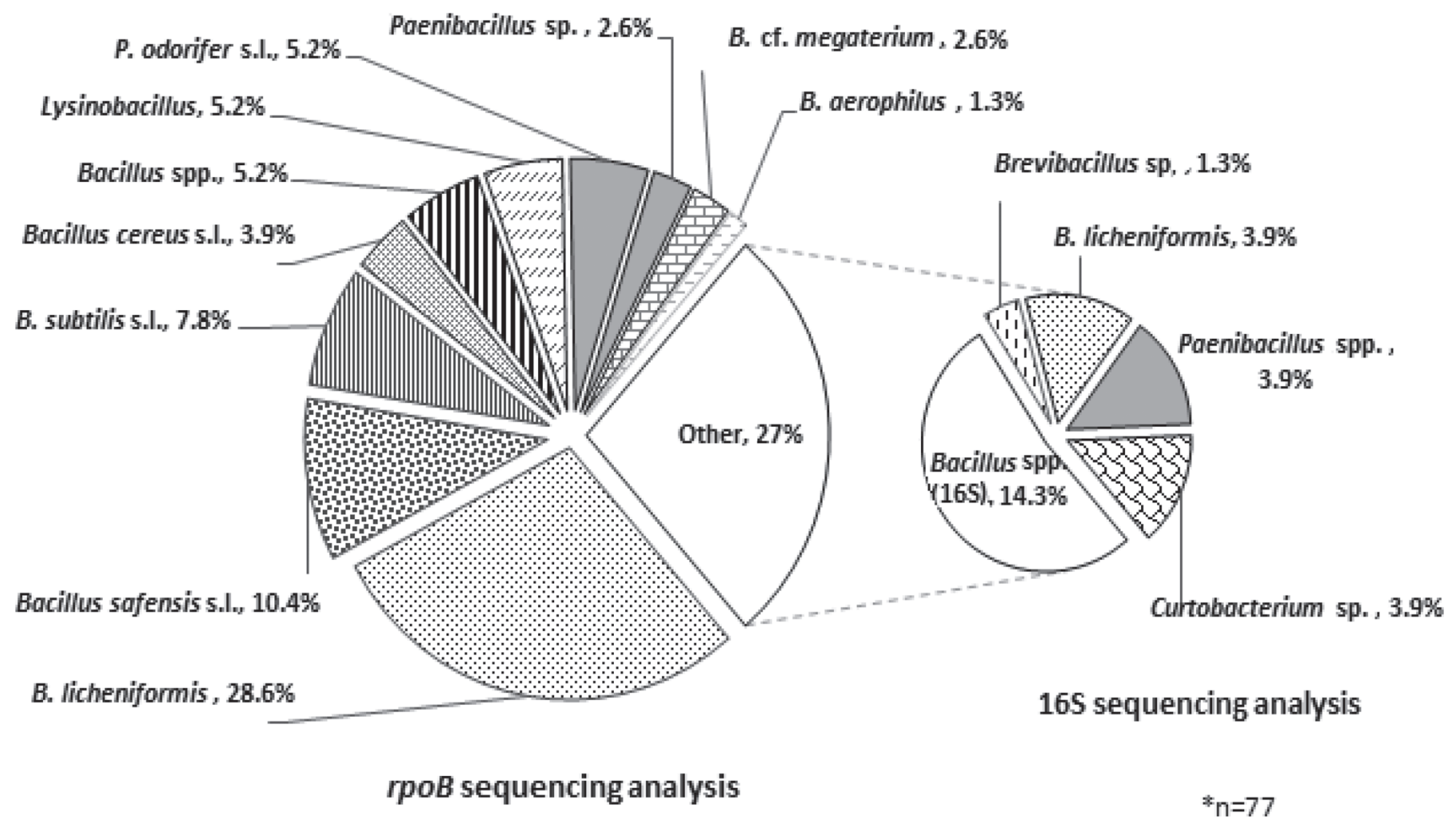

Figure 5. Identification of isolates from raw milk during fall 2014 using the $r p o B$ gene and the 16S DNA portion $(\mathrm{n}=$ number of total strains identified). B. = Bacillus, $P .=$ Paenibacillus, s.l. = sensu lato.

were combined and pie charts were used for seasons spring 2014 (Figure 4) and fall 2014 (Figure 5). The prevalence of each species is expressed in a percentage basis of the number of isolates (n) obtained from raw milk at the processing facility for each season.

Because isolates were obtained from samples to represent diversity rather than their true prevalence, the data represented by these pie charts should be interpreted with caution. The prevalence reported by the charts does not directly correlate with the prevalence of the isolates in the bacterial population of raw milk samples, but rather the distribution of isolates when a wider diversity was sought during isolation. Nonetheless, an overwhelming high prevalence of some isolates (i.e., B. licheniformis) could be an indication of their true high occurrence among the bacterial population of the raw milk samples.

According to the prevalence described in the pie charts, B. licheniformis seems to be the most common species present in raw milk for both seasons, spring 2014 (Figure 4) and fall 2014 (Figure 5). Indeed, the same proportion of $B$. licheniformis among isolates were found in both seasons, accounting for slightly more than $30 \%$ of all species found (combining results from $16 \mathrm{~S}$ and $r p o B$ sequencing analysis). Even though B. licheniformis (AT001) has been the most prevalent strain in different studies (including the present study), this AT has not shown ability to grow under refrigeration temperature according to Ivy et al. (2012). Therefore, it may not be an issue for the fluid milk industry. However, other dairy sectors, such as the milk powder industry, could be affected by the high prevalence of this Bacillus species. Indeed, this species seems to be present in milk powder with high prevalence (Miller et al., 2015).

\section{Genetic Diversity of Isolates Obtained from Pasteurized and Concentrated Milk}

The bacterial diversity found in pasteurized milk samples is described in Figure 6. As described previously, 2 samples were analyzed per season, with 14 strains sequenced from spring samples and 13 isolates sequenced from fall samples. The percentage shown in Figure 6 only indicates the number of times a particular species was found in pasteurized milk samples based on the total number of isolates obtained from this product. In general, similar species and taxonomic groups found 


\section{Pasteurized milk}
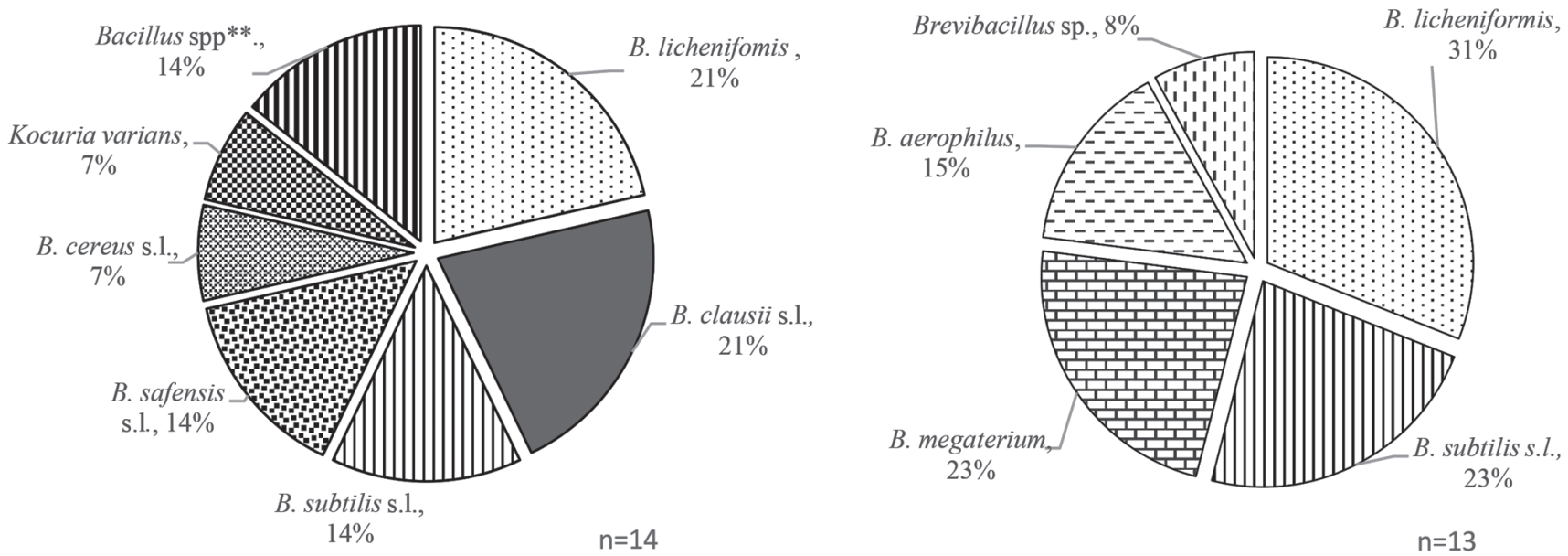

Concentrated milk

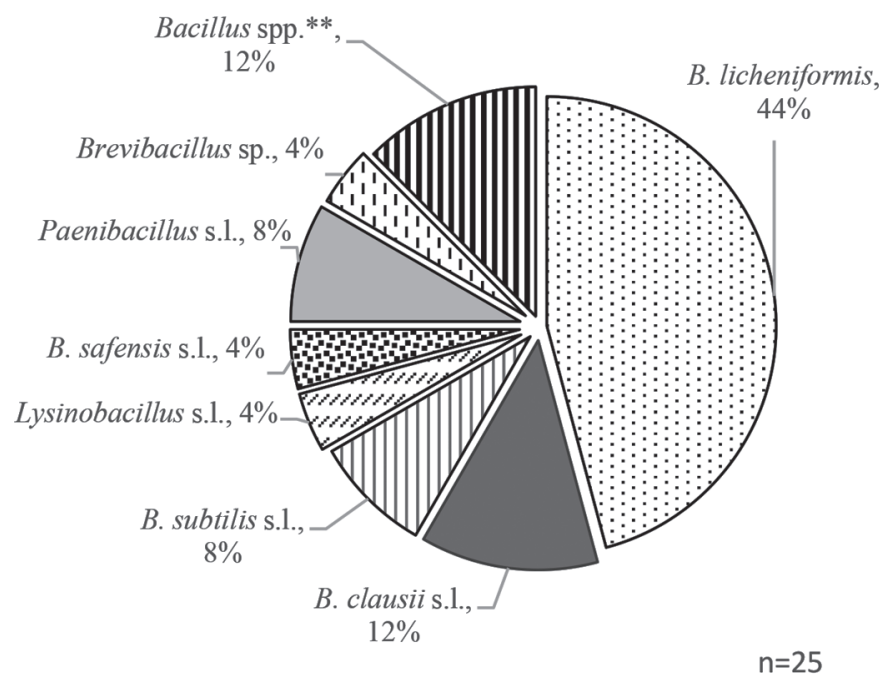

Spring 2014

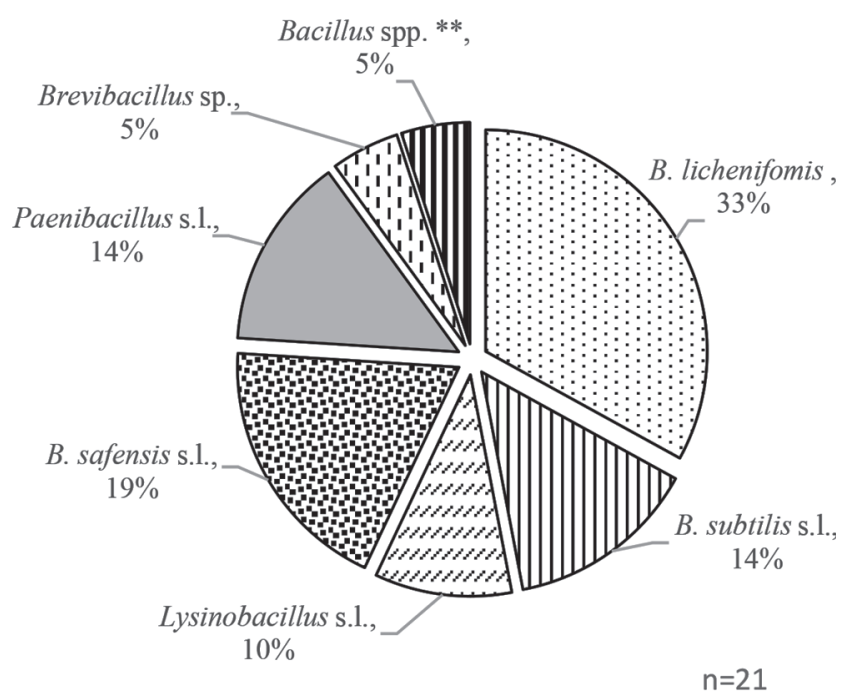

Fall 2014

Figure 6. Identification of isolates collected from pasteurized and concentrated milk during spring and fall 2014. $\mathrm{n}=$ represents the number of isolates obtained from each product in each season; ${ }^{*}=$ identification performed using $16 \mathrm{~S}$ DNA portion. B. $=$ Bacillus, s.l. $=$ sensu lato.

in pasteurized milk were also found in the raw milk. This finding suggests that spore-forming bacteria present in raw milk may survive the processing conditions and become associated with pasteurized milk.

Kocuria varians (formally known as Micrococcus varians) was part of the identified isolates in pasteurized milk and has not been previously described in association with milk in Nebraska (Estrada, 2014). This bacterium has shown resistance to heat in pasteurized milk, as previously described by Fromm and Boor
(2004). According to their results, this strain does not seem to have the ability to grow under refrigeration temperature, only being identified among isolates from the early stages of refrigerated milk storage.

The bacterial diversity associated with concentrated milk was determined using the same methods as for pasteurized and raw milk, and these results are shown as pie charts in Figure 6. Psychrotrophic spore-formers are usually the main concern for the fluid milk industry; however, for the concentrated milk industry, mesophilic 
and thermophilic strains are also important due to the potential use of this product as ingredient for milk powder or other dairy products. Milk powder requires low spore counts regardless of their growth profile; therefore, all spore-formers that survive pasteurization and condensation should be considered as a potential issue for this dairy sector.

Sequencing analysis revealed that Paenibacillus spp. were found in some of the analyzed concentrated milk (3/6 collected samples). The 2 Paenibacillus spp. isolates found in spring (Figure 6) were identical AT and had not been previously associated with raw milk or environmental samples from farms in Nebraska (Estrada, 2014). Interestingly, the very same AT has been identified by other researchers as Paenibacillus cf. peoriae (FSL J3-120; Vangay et al., 2013) and has been associated with similar processing environments and raw milk from other regions in the United States (Trmčić et al., 2015). Because this particular strain has the ability to survive all heat processing conditions at the concentrated milk plant, it could potentially contaminate other dairy products when concentrated milk is used as an ingredient, especially in reconstituted dairy products. In fact, this AT has been recognized as potentially problematic in refrigerated dairy products due to its ability to grow at low temperature and produce $\beta$-galactosidase, lipase, and proteinase at refrigerated conditions (Trmčić et al., 2015).

Similarly, during the fall season, Paenibacillus isolates were also found in concentrated milk representing 3 different AT. Unfortunately, identification was only possible at the genus level by the $16 \mathrm{~S}$ portion of the DNA. The presence of multiple AT in spring and fall suggests that Paenibacillus survival may be common in the concentrated milk process. However, the ability of Paenibacillus spp. to survive all the way to the production of milk powder should further be investigated.

Among the isolates obtained from concentrated milk in the spring and fall 2014, one of the most prevalent species, once again, was B. licheniformis (Figure 6). This species is also the most prevalent among all analyzed samples, including raw milk (Figures 4 and 5), pasteurized milk, and concentrated milk (Figure 6 ). This high prevalence in processed products shows the ability of this species to survive throughout the processing conditions from raw milk to concentrated milk. In general, the genetic diversity of the 3 products evaluated was quite similar as it can be observed in Figure 3, as similar phylogenetic clusters were found in raw, pasteurized, and concentrated milk.

Scientists from Nigeria were able to identify $B . l i$ cheniformis ( $60 \%$ occurrence), B. stearothermophilus (73\% occurrence), and B. subtilis (93\% of the analyzed samples) as the most prevalent spore-former species in evaporated milk (Edema and Akingbade, 2007). Among other characteristics, B. licheniformis is well known for being able to grow under mesophilic and facultativethermophilic conditions $\left(55^{\circ} \mathrm{C}\right.$; Burgess et al., 2010; Moatsou and Moschopoulou, 2014). Therefore, potential growth and association of this species with the pasteurized and concentrated milk chain could be an issue during processing, especially in warmer equipment such as heat exchangers or evaporators.

When isolates recovered from samples incubated at $55^{\circ} \mathrm{C}$ were evaluated, the results identified B. licheniformis as the most prevalent organism with the ability to grow at this temperature (with a prevalence of 17 out of 23 isolated strains). Other species that showed ability to grow under thermophilic temperatures were $B$. subtilis (3/23), Brevibacillus spp. (2/23), and Bacillus sonorensis $(1 / 23)$.

Among thermophilic spore-formers associated with dairy products, Anoxybacillus spp. have often been found in powder milk according to Reginensi et al. (2011); however, it seems that this organism is mostly associated with the actual processing of powders rather than with raw milk. Multiple studies have not necessarily found Anoxybacillus spores in raw milk, but did report their presence in the final milk powder (Ronimus et al., 2003; Scott et al., 2007; Yuan et al., 2012). Similarly, in our study no Anoxybacillus spp. were found in association with raw, pasteurized, or concentrated milk, suggesting that perhaps this organisms could be mostly associated with the last processing steps of milk powder production (Burgess et al., 2010). Another explanation for not finding Anoxybacillus spp. in the samples evaluated in our research could be their poor growth during the enrichment procedure carried out at $55^{\circ} \mathrm{C}$, as it has been reported that their optimum growth temperature could be around $65^{\circ} \mathrm{C}$ (Burgess, et al., 2010).

Other spore-forming bacteria that may be of concern to the dairy industry include Bacillus clausii and $B$. subtilis, which we found in association with concentrated milk. These species have been previously reported as capable of producing gas and reducing nitrate in cheeses, which reduces the protection provided by this compound against Clostridium spp. (Quiberoni et al., 2008; De Jonghe et al., 2010). However, further studies would be necessary to determine if the strains isolated in this research would also have the ability to affect cheese quality when produced from concentrated milk containing these isolates.

\section{CONCLUSIONS}

The spore-former bacterial diversity associated with raw milk collected at the concentrated milk processing facility did not differ between the 2 analyzed seasons 
(spring and fall). Based on isolate identification and their relatedness, strains found in raw, pasteurized, and concentrated milk were determined to be similar, with B. licheniformis the most common spore-former species from all collected samples. Even though a wide variety of species were present in raw milk, it is important to highlight that the Paenibacillus cluster ( $P$. odorifer, $P$. graminis, and $P$. cookii) was associated with bacterial growth of heat-treated milk samples when stored under refrigeration temperature $\left(7^{\circ} \mathrm{C}\right)$. This bacterial cluster was also found in concentrated milk in both seasons. More importantly, these bacterial strains had not been previously associated with concentrated milk. Due to their ability to cause spoilage under refrigeration, this shows the potential risk associated with the transferring of these problematic organisms into other refrigerated dairy products. Among thermophilic strains, the most common one associated with concentrated milk was B. licheniformis, and to a lesser extent B. subtilis and Brevibacillus spp. Because these strains were found in concentrated milk, they may be translocated to other dairy products, such as milk powder, becoming a quality problem. The results of this research highlight the importance of understanding spore-formers associated with the processing of condensed milk, which then may allow for specific interventions to be applied to control these microorganisms in this processing chain. Such interventions may include changes in cleaning and sanitation protocols, closer evaluation of run times, or changes in processing parameters.

\section{ACKNOWLEDGMENTS}

This project was supported by the Midwest Dairy Association (St. Paul, MN). The authors also thank the processing facility and their staff which helped during sample collection and provided valuable information for this research.

\section{REFERENCES}

Bienvenue, A. 2014. Summary of 2013-U.S. Dairy spore seminar and spore 101. Session 1, page 3, slide 6 in Spore Conference, Denver, CO. US Dairy Export Council, Arlington, VA.

Buehner, K. P., S. Anand, G. Djira, and A. Garcia. 2014. Corrigendum to Prevalence of thermoduric bacteria and spores on 10 Midwest dairy farms. J. Dairy Sci. 97:8009-8016.

Burgess, S. A., D. Lindsay, and S. H. Flint. 2010. Thermophilic bacilli and their importance in dairy processing. Int. J. Food Microbiol. 144:215-225.

De Jonghe, V., A. Coorevits, J. De Block, E. Van Coillie, K. Grijspeerdt, L. Herman, P. De Vos, and M. Heyndrickx. 2010. Toxinogenic and spoilage potential of aerobic spore-formers isolated from raw milk. Int. J. Food Microbiol. 136:318-325.

Drancourt, M., V. Roux, P.-E. Fournier, and D. Raoult. 2004. rpoB gene sequence-based identification of aerobic gram-positive cocci of the genera Streptococcus, Enterococcus, Gemella, Abiotrophia, and Granulicatella. J. Clin. Microbiol. 42:497-504.
Durak, M. Z., H. I. Fromm, J. R. Huck, R. N. Zadoks, and K. J. Boor. 2006. Development of molecular typing methods for Bacillus spp. and Paenibacillus spp. isolated from fluid milk products. J. Food Sci. 71:M50-M56.

Edema, M., and O. Akingbade. 2007. Incidence of spore-forming bacteria in unsweetened evaporated milk brands in Nigeria. Niger. Food J. 25:138-145.

Estrada, M. 2014. Tracking heat resistant sporeforming bacteria in the milk chain: A farm to table approach. MS, Department of Food Science and Technology. University of Nebraska, Lincoln.

FDA. 2015. Grade "A" pasteurized milk ordinance 2015. Accessed Jul. 25, 2016. http://www.fda.gov/downloads/Food/ GuidanceRegulation/GuidanceDocumentsRegulatoryInformation/ Milk/UCM513508.pdf.

Fromm, H. I., and K. J. Boor. 2004. Characterization of pasteurized fluid milk shelf-life attributes. J. Food Sci. 69:M207-M214.

Greisen, K., M. Loeffelholz, A. Purohit, and D. Leong. 1994. PCR primers and probes for the 16S rRNA gene of most species of pathogenic bacteria, including bacteria found in cerebrospinal fluid. J. Clin. Microbiol. 32:335-351.

Huck, J. R., B. H. Hammond, S. C. Murphy, N. H. Woodcock, and K. J. Boor. 2007a. Tracking spore-forming bacterial contaminants in fluid milk-processing systems. J. Dairy Sci. 90:4872-4883.

Huck, J. R., M. Sonnen, and K. J. Boor. 2008. Tracking heat-resistant, cold-thriving fluid milk spoilage bacteria from farm to packaged product. J. Dairy Sci. 91:1218-1228.

Huck, J. R., N. H. Woodcock, R. D. Ralyea, and K. J. Boor. 2007b. Molecular subtyping and characterization of psychrotolerant endospore-forming bacteria in two New York State fluid milk processing systems. J. Food Prot. 70:2354-2364.

Ivy, R. A., M. L. Ranieri, N. H. Martin, H. C. den Bakker, B. M. Xavier, M. Wiedmann, and K. J. Boor. 2012. Identification and characterization of psychrotolerant sporeformers associated with fluid milk production and processing. Appl. Environ. Microbiol. 78:1853-1864.

Karaman, A., and V. Alvarez. 2014. Microbiology of evaporated, condensed and powdered milk Pages 271-287 in Dairy Microbiology and Biochemistry: Recent Developments. B. H. Ozer and G. Akdemir-Evrebdilek, ed. CRC Press, Boca Raton, FL.

Laird, D., S. Gambrel-Lenarz, F. Scher, T. Graham, and R. Reddy. 2004. Microbial count methods. Pages 153-186. in Standard Methods for the Examination of Dairy Products. 17th ed. H. W. A. J. Frank, ed. American Public Health Association, Washington, DC.

Magnusson, M., A. Christiansson, and B. Svensson. 2007. Bacillus cereus spores during housing of dairy cows: Factors affecting contamination of raw milk. J. Dairy Sci. 90:2745-2754.

Meer, R., J. Baker, F. Bodyfelt, and M. Griffiths. 1991. Psychrotrophic Bacillus spp. in fluid milk products: A review. J. Food Prot. 54:969-979.

Miller, R. A., D. J. Kent, M. J. Watterson, K. J. Boor, N. H. Martin, and M. Wiedmann. 2015. Spore populations among bulk tank raw milk and dairy powders are significantly different. J. Dairy Sci. 98:8492-8504.

Moatsou, G., and E. Moschopoulou. 2014. Microbiology of raw milk. Pages 1-31 in Dairy Microbiology and Biochemistry. B. H. Ozer and G. Akdemir-Evrebdilek, ed. CRC Press, Boca Raton, FL.

Quiberoni, A., D. Guglielmotti, and J. Reinheimer. 2008. New and classical spoilage bacteria causing widespread blowing in Argentinean soft and semihard cheeses. Int. J. Dairy Technol. 61:358-363.

Ranieri, M. L., J. R. Huck, M. Sonnen, D. M. Barbano, and K. J. Boor. 2009. High temperature, short time pasteurization temperatures inversely affect bacterial numbers during refrigerated storage of pasteurized fluid milk. J. Dairy Sci. 92:4823-4832.

Rasko, D. A., J. Ravel, O. A. Økstad, E. Helgason, R. Z. Cer, L. Jiang, K. A. Shores, D. E. Fouts, N. J. Tourasse, S. V. Angiuoli, J. Kolonay, W. C. Nelson, A.-B. Kolstø, C. M. Fraser, and T. D. Read. 2004. The genome sequence of Bacillus cereus ATCC 10987 reveals metabolic adaptations and a large plasmid related to Bacillus anthracis pXO1. Nucleic Acids Res. 32:977-988.

Reginensi, S. M., M. J. Gonzalez, J. A. Olivera, M. Sosa, P. Juliano, and J. Bermudez. 2011. RAPD-based screening for spore-forming 
bacterial populations in Uruguayan commercial powdered milk. Int. J. Food Microbiol. 148:36-41.

Ronimus, R. S., L. E. Parker, N. Turner, S. Poudel, A. Ruckert, and H. W. Morgan. 2003. A RAPD-based comparison of thermophilic bacilli from milk powder. Int. J. Food Microbiol. 85:45-61.

Rothman, R. E., M. D. Majmudar, G. D. Kelen, G. Madico, C. A. Gaydos, T. Walker, and T. C. Quinn. 2002. Detection of bacteremia in emergency department patients at risk for infective endocarditis using universal $16 \mathrm{~S}$ rRNA primers in a decontaminated polymerase chain reaction assay. J. Infect. Dis. 186:1677-1681.

Scott, S. A., J. D. Brooks, J. Rakonjac, K. M. R. Walker, and S. H Flint. 2007. The formation of thermophilic spores during the manufacture of whole milk powder. Int. J. Dairy Technol. 60:109-117.

Tamura, K., G. Stecher, D. Peterson, A. Filipski, and S. Kumar. 2013. MEGA6: Molecular evolutionary genetics analysis version 6.0. Mol. Biol. Evol. 30:2725-2729.

te Giffel, M. C., A. Wagendorp, A. Herrewegh, and F. Driehuis. 2002. Bacterial spores in silage and raw milk. Antonie van Leeuwenhoek 81:625-630.
Trmčić, A., N. H. Martin, K. J. Boor, and M. Wiedmann. 2015. A standard bacterial isolate set for research on contemporary dairy spoilage. J. Dairy Sci. 98:5806-5817.

Vangay, P., E. B. Fugett, Q. Sun, and M. Wiedmann. 2013. Food microbe tracker: A web-based tool for storage and comparison of food-associated microbes. J. Food Prot. 76:283-294.

Watterson, M. J., D. Kent, K. Boor, M. Wiedmann, and N. Martin. 2014. Evaluation of dairy powder products implicates thermophilic sporeformers as the primary organisms of interest. J. Dairy Sci. 97:2487-2497.

Yuan, D.. G. Liu, D. Ren, D. Zhang, L. Zhao, C. Kan, Y. Yang, W. Ma, Y. Li, and L. Zhang. 2012. A survey on occurrence of thermophilic bacilli in commercial powders in China. Food Contr. $25: 752-757$. 